\title{
Evidence for the role of German final devoicing in pre-attentive speech processing: a mismatch negativity study
}

\author{
Hubert Truckenbrodt ${ }^{1,2} *$, Johanna Steinberg ${ }^{3}$, Thomas K. Jacobsen ${ }^{4}$ and Thomas Jacobsen ${ }^{4}$ \\ ${ }^{1}$ Centre for General Linguistics, Berlin, Germany \\ 2 Institut für deutsche Sprache und Linguistik, Humboldt University, Berlin, Germany \\ ${ }^{3}$ Department of Psychology, University of Leipzig, Leipzig, Germany \\ ${ }^{4}$ Experimental Psychology Unit, Helmut Schmidt University/University of the Federal Armed Forces Hamburg, Hamburg, Germany
}

\section{Edited by:}

Ulrike Domahs, University of

Marburg, Germany

Reviewed by:

Carsten Eulitz, University of Konstanz,

Germany

Matthew Winn, University of

Wisconsin-Madison, USA

Burkhard Maess, Max Planck Institute

for Human Cognitive and Brain

Sciences, Germany

\section{*Correspondence:}

Hubert Truckenbrodt, ZAS,

Schützenstraße 18, 10117 Berlin,

Germany

e-mail: truckenbrodt@

zas.gwz-berlin.de
Results of a mismatch negativity experiment are reported in which the pre-attentive relevance of the German phonological alternation of final devoicing (FD) is shown in two ways. The experiment employs pseudowords. (1) A deviant [vus] paired with standard/vuzə/ did not show a mismatch effect for the voicing change in /z/ versus [s] because the two can be related by FD. When standard and deviant were reversed, the two could not be related by FD and a mismatch effect for the voicing difference occurred. (2) An ill-formed deviant that violates FD, * [vuz], triggered mismatch effects that were plausibly attributed to its ill-formedness. The results show that a syllable-related process like FD is already taken into account by the processing system in early pre-attentive processing.

Keywords: mismatch negativity (MMN), event-related potentials (ERP), phonological rules, final devoicing, phonotactics, German, pre-attentive processing

\section{INTRODUCTION}

\section{NEURAL PROCESSING AND MISMATCH NEGATIVITY}

Electrophysiological methods like the electroencephalogram (EEG) and the magnetoencephalogram (MEG) provide the possibility to obtain online insight into the perceptual process. This includes the pre-conscious and pre-attentive or automatic stages of processing. There is a sequence of positive-negative-positive deflections in the event-related potential (ERP), of which the first negative deflection (N100) typically peaks around $100 \mathrm{~ms}$ after the occurrence of a transient sound like an isolated vowel. The N100 has been found for speech sounds and for non-speech sounds. For speech sounds, the processing in this early stage shows, for one thing, characteristics of acoustic processing that are independent of phonological categories (e.g., Sharma and Dorman, 2000). At the same time, a number of studies have demonstrated the effect of phonological categories in this early stage: acoustically equidistant stimuli cluster along phonological categories. This can be observed in the exact timing of the effect ([a] at $95 \mathrm{~ms}$, [u] at $120 \mathrm{~ms}$; see Roberts et al., 2004), and in the location of the activity in the brain (Obleser et al., 2004).

The mismatch negativity (MMN) component of the ERP allows for some indirect insights into this early phase of processing. MMN is typically obtained in a classic passive oddball paradigm. In this experimental protocol, a sequence of identical sounds, the standards, (for example [a]), is interrupted occasionally by another sound, the deviant, (for example [u]), as in [a a a u ...]. A standard experimental design, called reversed oddball design, will test [a a a u ...] with standard [a] and deviant [u] as well as [u u u a ...] with standard $[\mathrm{u}]$ and deviant $[\mathrm{a}]$, both with a considerable number of repetitions. The activities of standard $[\mathrm{u}]$, deviant $[\mathrm{u}]$, standard [a], and deviant [a] are then each averaged separately, and the difference waves are calculated from the ERPs either by subtracting the ERP of the original standard from the deviant ERP or by subtracting the ERPs elicited by the same stimulus when presented as standard and as deviant from the reversed oddball condition. A significant negative-going deflection in the difference wave calculated from the deviant and the standard ERP may be evidence for the MMN ERP component (Näätänen, 1992, 2001). This often occurs in the time range of 100$250 \mathrm{~ms}$ after the beginning of the deviating sound (e.g., Schröger, 2005).

Mismatch negativity studies also show the early effect of phonological categories (see for example Dehaene-Lambertz et al., 2000; Phillips et al., 2000); the evidence for this comes in part from comparisons between speakers of different languages (Näätänen et al., 1997; Winkler et al., 1999; Peltola et al., 2003). The speakers may react differently to a given sound contrast depending on the sound inventory of their native language.

\section{PREVIOUS MMN-STUDIES ON PHONOTACTIC RESTRICTIONS}

Some other studies have investigated the effects of phonological rules or phonotactic constraints in MMN protocols. DehaeneLambertz et al. (2000) investigated the Japanese restriction that the syllable coda allows only place-assimilated nasals (and the first part of a geminate; cf. Itô, 1986). When Japanese listeners hear a sequence like [igmo] they perceive the presence of an additional vowel as in [igumo]. The additional vowel makes the sequence well-formed in Japanese. French speakers do not hear such an 
additional vowel. In an MMN experiment, pairs like [igmo] and [igumo] were investigated for effects of the vowel epenthesis. In Japanese speakers, there was no MMN effect, while in French speakers there was. As the authors note, these results "suggest that the impact of phonotactics takes place early in speech processing and support models of speech perception, which postulate that the input signal is directly parsed into the native language phonological format" (p. 635). Since we were interested, in our own studies, in effects of processing that take place outside of the focus of attention, we mention that the participants of the study of Dehaene-Lambertz et al. (2000) were instructed to pay attention to the stimuli and to answer for each five-stimulus sequence whether the fifth (the deviant) was different from the preceding four.

Mitterer and Blomert (2003) investigated optional nasal place assimilation in Dutch compounds (in terms of lexical phonological theory: postlexical assimilation). They paired the unassimilated [tuinbank] with the assimilated [tuimbank] (both "garden bank"), both of which are possible forms of this word in Dutch, while participants were watching a silent movie. This contrast was compared with the pairing of [tuinstoel] and [tuimstoel]. While the difference between [tuin] and [tuim] was identical in the two stimulus pairs, the change was not motivated by assimilation in [tuimstoel]. A significant difference between standard and deviant was found in the latter pair, but not in the former pair where the assimilation process relates the two forms. Therefore, the regressive assimilation process is relevant to early pre-attentive processing.

Flagg etal. (2006) investigated an assimilatory nasalization process in English with an MEG study. In /ama/ the first vowel optionally gets nasalized by the following nasal as in [ãma]. Flagg etal. (2006) classified this alternation as phonological assimilation, though we point out that the process more likely is to be seen as coarticulatory, i.e., phonetic in nature. Such a nasalized vowel was spliced before a non-nasal consonant as in [ãba]. The participants of the experiment were watching silent movies during passive stimulation. A latency delay was found for the M50 response elicited by the incongruent plosive in [ãba] compared to [aba]. This indicated that the nasalization process was relevant to very early pre-attentive processing.

Steinberg etal. (2010a,b, 2011) investigated a German allophonic alternation related to two dorsal fricative allophones both represented orthographically as "ch." The palatal allophone of this fricative occurs after front vowels ([diçt ] dicht'dense') and the velar allophone after back vowels ([doxt] Docht 'wick'). This alternation is also known as dorsal fricative assimilation (DFA). From a range of different experiments that all provide evidence for the effect of DFA in pre-attentive processing, we here choose one for presentation: the ill-formed non-word $*[\varepsilon x]$ combines a velar fricative with a front vowel. Contrasted with the well-formed pseudoword $[\mathrm{ox}]$ as standard, there was a mismatch effect attributable to the different vowels. The fricatives are segmentally identical, so that the deviant $[\mathrm{ox}]$ did not show an MMN due to the fricative in the comparison condition. However, the ill-formed deviant * $[\varepsilon \mathrm{x}]$ elicited an additional MMN response attributable to the fricative. This response was temporally separated from the vowel-related
MMN and attributed to the abstract phonotactic ill-formedness of the deviant.

In the present study on final devoicing (FD) in German, we continue our investigation of bona fide productive lexical phonological rules in German, i.e., of alternations that apply obligatorily, without idiosyncratic exceptions and within the domain of words or pseudowords, but not across words or pseudowords.

\section{FINAL DEVOICING}

Final devoicing operates on what has classically been analyzed as a voicing contrast (see e.g., Rubach, 1990; Hall, 1992). Jessen and Ringen (2002) have argued that the contrast instead involves the feature [spread glottis] for the plosives, and Beckman et al. (2009), building on this, have argued that the German fricatives are specified for both [spread glottis] and [voiced] (see also Vaux, 1998 for arguments that voiceless fricatives are specified [+spread glottis] across languages). In the present experiment, we employed a voicing distinction in fricatives. Assuming such a dual specification, we expect no effects of lexical underspecification, which have been argued to affect MMN by Eulitz and Lahiri (2004), Cornell et al. (2011, 2013), and Scharinger et al. (2012). Instead, voiced fricatives would be specified [+voiced] and voiceless ones would be specified [ + spread glottis] in the mental lexical entries.

The German plosives and fricatives that allow such a laryngeal contrast, here transcribed in terms of voicing, are $[\mathrm{p} / \mathrm{b}, \mathrm{t} / \mathrm{d}, \mathrm{k} / \mathrm{g}$, $\mathrm{f} / \mathrm{v}, \mathrm{s} / \mathrm{z}]$. Both members of each pair can occur in the onset of a syllable before a vowel. In the classical analysis, the voiced values become voiceless in a syllable coda (Rubach, 1990; Hall, 1992). Thus, the two genitive forms [ra.d-əs] (Rades 'wheel-GEN') and [ra.t-əs] (Rates 'advice-GEN') distinguish [d] and [t] in the syllable onset before a vowel. However, in the nominative form, without the genitive suffix [-əs], the forms are identically pronounced [ra:t] ('wheel'/'advice'). Here, /d/ and /t/ are in the syllable coda and only the voiceless pronunciation [t] occurs. The change from /d/ in the mental lexical entry / $\mathrm{rad} /$ to $[\mathrm{t}$ ] in the pronunciation in coda position is called final devoicing (FD). There are different suggestions about the best way of describing and capturing the correct environment (see e.g., Lombardi, 1991, 1999; Steriade, 1997; Beckman et al., 2009). There is also a debate about whether the voicing neutralization is phonetically complete (see e.g., Port and O'Dell, 1985; Beckman et al., 2009). However, it is clear that the change takes place obligatorily in a set of core environments that include the word-final position, that there are no lexically marked exceptions, and that the change is bounded by the word.

Hwang et al. (2010) showed that English voicing agreement in consonant clusters as in their pseudoword stimuli [ $v \mathrm{ts}]$ and [ $v \mathrm{dz}$ ] lead to processing difficulties in non-agreeing clusters like * [ $v \mathrm{ds}]$, which were not found in non-agreeing clusters like * [vtz]. Poeppel and Monahan (2011, p. 947f.) refer to results of a related MEG experiment in which a distinction between [ $\mho \mathrm{ts}]$ and * [ $\mathrm{ds}]$ was found around $150 \mathrm{~ms}$ after the onset of the fricative. Hwang et al. (2010) interpret their results in terms of the underspecification for voicing of voiceless plosives in English postulated by Lombardi (1991, 1999): speakers predict a following voiced sound after [d] in $*[\mho \mathrm{ds}]$ but do not predict a following voiceless sound after [t] in $*[\mho t z]$ because $[t]$ is underspecified for voicing. We think that 
this explanation may apply to a phonological surface structure in which the position preceding the fricative is conceivably one of laryngeal neutralization (see Steriade, 1997). It is conceivable that the voicelessness of $[\mathrm{t}$ ] preceding a fricative may be accounted for by laryngeal neutralization by the processing system, while the voicing of $[d]$, if followed by a fricative, can only be licensed by agreement with the fricative. Our assumptions about the underlying featural specifications in German are thus not in conflict with these interesting results.

The voicing distinction between obstruents in German is phonetically implemented in several ways depending both on the manner of articulation and on the relative position of the sound. As we will focus on fricatives in intervocalic and final position in our study (see Experimental design), we will limit the following overview over phonetic voicing cues to these instances. Because in German, the phonetic implementations of the voicing contrast are - at least partly - neutralized in final positions, we also attend to voicing parameters obtained in languages like English in which FD is not operative. As shown by various phonetic studies (for an overview of the literature on the voicing distinction in German fricatives, see Jessen, 1998, pp. 65-66, 96; phonetic evidence on English fricatives is reviewed for instance by Stevens et al., 1992, and Maniwa and Jongman, 2009) the voicing distinction between fricatives is mainly coded by three kinds of parameters: first, the duration of the fricative (as reflected by the duration of friction noise in the acoustic signal) is shorter in voiced compared to voiceless fricatives. Preceding full vowels show - to some degree the reversed durational pattern. Second, there are several spectral indicators for fricative voicing, most importantly the presence of periodic low-frequency energy during the fricative (reflecting vocal fold vibrations). Additionally, voiced fricatives are characterized by a lower Center of Gravity (COG) and higher variance compared to voiceless fricatives (cf. Maniwa and Jongman, 2009). Third, fricative voicing is indicated by a greater extent of the F1 transitions of preceding or following adjacent vowels (e.g., Stevens et al., 1992). Furthermore, vowels following a voiced fricative have been shown to begin with lower $\mathrm{F}_{0}$ than vowels after voiceless ones (Jessen, 1998).

\section{AN ASYMMETRY BETWEEN STANDARDS AND DEVIANTS}

There is an interesting asymmetry in the roles played by standard and deviant in processing the oddball stimulation. Since the standard is repeated a number of times, and the pauses between the repetitions give sufficient time for it to be recognized as a particular phonological sound or sound sequence, it seems, put simply, that the expectation for another standard is phonologically represented, or represented in more abstract terms (Näätänen, 2001). The deviant, on the other hand, is just coming into the system and its initial processing is ongoing at the time when the mismatch against the standard arises.

Eulitz and Lahiri (2004), Cornell et al. (2011, 2013), and Scharinger et al. (2012) have argued that the standard can in certain ways be seen as similar to a mental lexical entry, likewise abstractly represented, and that the deviant can be seen as similar to the incoming acoustic information that the system seeks to match to an abstract lexical entry. They have argued that lexical underspecification of features matters for MMN in a way that can be understood in these terms. A crucial aspect of the asymmetry for our experiment is that it provides a direction of application of FD: if it applies in an oddball protocol in early pre-attentive processing, it should apply in pairs in which the standard corresponds to a possible mental lexical entry to which FD could apply, and in which the deviant can be seen as similar to a spoken word to which FD has applied. For ease of exposition we therefore adopt some notation of Cornell et al. (2013). The standards are provided with slashes /./ and the deviants with squared brackets [.]. This is parallel to the phonological notation where /./ is used for mental lexical entries and [.] for what is heard.

\section{EXPERIMENTAL DESIGN}

The experiment reported here addressed German FD in preattentive phonological processing. The stimuli employed were [vus], *[vuz], [vusə], and [vuzə] as depicted in Figure 1. We concentrated on four pair-wise contrasts each of which was employed twice with reversed roles of standard and deviant in the stimulations, resulting in a total of eight experimental conditions. As explained above, we marked the standard stimuli of the experimental conditions with /./ and the deviants with [.]. Our expectations were based on the similarities of standard stimuli to abstract phonological lexical representations on the one hand, and deviants to phonetic surface representations that are close to

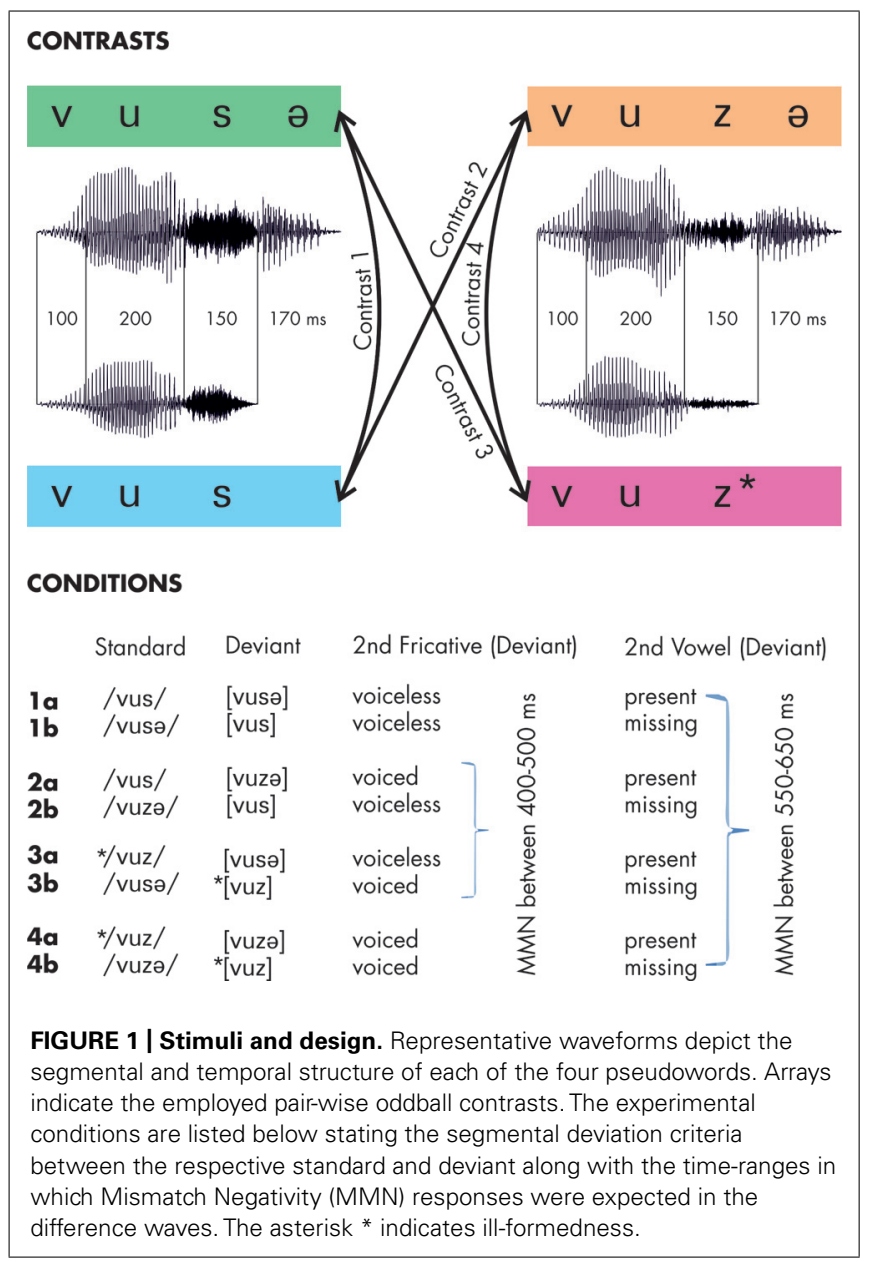


the acoustic input on the other hand (Näätänen, 2001; Eulitz and Lahiri, 2004).

Contrast 1 is what would be an alternation in German for an underlying voiceless $/ \mathrm{s} /$. There is no change in voicing of the fricative. Hence, we expected MMN elicitation both for the additional vowel in 1a and for the missing vowel in $1 \mathrm{~b}$.

In contrast 2 , stimuli differ with respect to the voicing of the second fricative. In condition $2 \mathrm{a}$, this change is phonologically unmotivated. Furthermore, the deviant differs due to its additional vowel. Here, we expected an MMN to be elicited by each of these changes. Run the other way around, as in condition $2 \mathrm{~b}$, the whole contrast between standard and deviant could be interpreted as an alternation in German for an underlying voiced / $\mathrm{z}$ / in /vuzə/, with FD in [vus]. While the phonetic differences were the same in $2 \mathrm{a}$ and $2 \mathrm{~b}$, we expected the respective MMN patterns to reflect that standard and deviant were phonologically related due to FD in $2 b$ but not in $2 \mathrm{a}$.

Contrasts 3 and 4 employ the ill-formed stimulus *[vuz]. It is ill-formed because FD would obligatorily turn it into [vus] in German. In contrast 3 , the deviant enters into an unmotivated voicing alternation of the second fricative in both conditions. In addition, the stimuli differed with respect to the presence or absence of the final vowel. Consequently, we expected to find MMN for each of these segmental differences in both conditions. Furthermore, we were interested in whether we would find an additional effect attributable to the ill-formedness of * [vuz] when being presented as deviant. As the phonological violation * [vuz] coincided with the absence of the second vowel, we expected these mismatch responses to overlay, as reflected by a larger MMN amplitude in condition $3 \mathrm{~b}$ compared to $1 \mathrm{~b}$.

In contrast 4 , there is no change in voicing with respect to the second fricative, so no effects were expected in any corresponding time window. With respect to the difference in the final vowel, we were interested in whether condition 4 a would show reduced $\mathrm{MMN}$ compared to the remaining a-conditions; this may be expected as it would reflect a remedy of the violation of FD in the standard *[vuz]. In condition $4 \mathrm{~b}$, we again expect superimposed mismatch effects due to the ill-formedness of the deviant * [vuz] and due to the missing second vowel as in condition $3 \mathrm{~b}$.

\section{MATERIALS AND METHODS PARTICIPANTS}

Sixteen volunteers participated in the study (four male; median age was 26 years, range from 22 to 33), all of them right-handed and monolingual native speakers of German. Handedness was assessed using an inventory adopted from Oldfield (1971). All participants reported normal auditory and normal or correctedto-normal visual acuity and no neurological, psychiatric, or other medical problems. They gave informed written consent. The study conformed to The Code of Ethics of the World Medical Association (2013, Declaration of Helsinki).

\section{MATERIALS}

As described, four pseudowords were used as stimuli: [vus], [vusə], *[vuz], and [vuzə]. The stimuli are phonotactically well-formed in German, except for the non-word *[vuz], which fails to have undergone FD. The stimuli [vus], [vusə], * [vuz], and [vuzə] were articulated numerous times by a professional male speaker with a fundamental frequency $\left(\mathrm{F}_{0}\right)$ of about $100 \mathrm{~Hz}$, and digitally recorded with a $48 \mathrm{kHz}$ sampling rate and a 16 bit resolution using a RME Fireface 800 recording device (Audio AG, Haimhausen, Germany) and a Neumann U87 Microphone (Georg Neumann $\mathrm{GmbH}$, Berlin, Germany).

Stimulus preparation for ERP-experiments on speech processing is always a compromise. The point is to control for lower-level acoustic stimulus characteristics in order to avoid confounds with higher-level linguistic factors while on the same time keeping the stimuli as natural as possible and avoiding artifacts caused by manipulation. To assure some acoustic variability of the stimulus material, we selected 5 different utterances of each pseudoword resulting in a set of 20 pseudoword stimuli in total (see Eulitz and Lahiri, 2004; Jacobsen et al., 2004; Steinberg et al., 2012). However, the conflicting methodological requirements mentioned above concern our study in a special way. The phonological issue under investigation (i.e., the voicing distinction between $[s]$ and $[z]$ ) is also coded by the inherent durational differences both between the voided and voiceless fricatives and between the preceding vowels. Other sufficient voicing cues for fricative perception are the presence or absence of low frequency energy during the fricative in the acoustic signal and distinct F1 transitions on vowel-fricative and fricative-vowel boundaries. These cues are also highly reliable at least in intervocalic and final fricative position (as in our stimuli).

Based on these considerations we decided to normalize the segmental durations of the stimuli across contrasts and to base the voicing distinction only on spectral phonetic parameters. Durational normalization was performed using the time-domain pitch synchronous overlap add (TD-PSOLA) algorithm provided by Praat software (Boersma and Weenink, 2010). Segmental durations were equated by setting the initial fricative to $100 \mathrm{~ms}$ (mean original durations of [v] in ms: [vus] 129, [vusə] 119, [vuz] 102, [vuzə] 109), the full vowel to $200 \mathrm{~ms}$ (mean original durations of [u] in ms: [vus] 200, [vusə] 188, [vuz] 285, [vuzə] 203), the second fricative to $150 \mathrm{~ms}$ (mean original durations of [s] in ms: [vus] 329, [vusə] 177; of [z] in ms: [vuz] 259, [vuzə] 119) and the final vowel to $170 \mathrm{~ms}$ (mean original durations of schwa in ms: [vusə] 189, [vuzə] 167). Afterward, intensities were normalized using the root mean square (RMS) of the whole sound file.

Theoretically, the duration normalization bore two risks: first, originally voiced fricatives might be perceived as voiceless after the relative lengthening of the fricative and the shortening the preceding vowel. Second, the contrary effect might have occurred to the originally voiceless fricatives. However, our ERP data clearly indicate that a distinction in the fricative has been detected in both directions in contrasts 2 and 3 [see Analysis of the voicing change in the fricatives (contrasts 2 and 3)]. Nevertheless, we performed acoustic analyses after the manipulation procedures to ensure that sufficient phonetic information was left in the stimulus material coding the voicing distinction between the fricatives [v] and [s] and to test potential interactions with the syllabic position of the fricative. We tested both offset F1 transitions of the first vowel, and the first two spectral moments of the fricative.

Formant measures were taken from each single stimulus file as mean values within 20 ms analysis windows by using the linear 
prediction-based burg method (as implemented in Praat) with a pre-emphasis frequency of $50 \mathrm{~Hz}$. F1 measures were taken from the mid part (190-210 ms) and from the final part of the vowel (280-300 ms) by automatically determining maximally two formants below $2000 \mathrm{~Hz}$. F1-transitions were analyzed by means of a univariate mixed design analysis of variance (ANOVA) with the within-items factor TRANSITION (mid vowel/vowel offset) and the between-items factors FRICATIVE (voiceless/voiced) and SYLLABLE (mono-/bisyllabic). We found a main effect of the factor TRANSITION $\left(F_{1,16}=6.2 ; p=0.024 ; \eta_{\mathrm{p}}^{2}=0.279\right)$ and a significant interaction TRANSITION*FRICATIVE $\left(F_{1,16}=5.9\right.$; $\left.p=0.027 ; \eta_{\mathrm{p}}^{2}=0.269\right)$. As expected from the literature, the first vowel formant showed a significantly falling pattern when preceding the voiced fricative (F1 mid vowel: $357 \mathrm{~Hz} / \mathrm{F} 1$ vowel offset: $316 \mathrm{~Hz}$; main effect TRANSITION in a broken down twoway ANOVA with TRANSITION and SYLLABLE: $F_{1,8}=13.8$; $\left.p=0.006 ; \eta_{\mathrm{p}}^{2}=0.633\right)$ while the $\mathrm{F} 1$ transition remained steady-state when being followed by the voiceless fricative (F1 mid vowel: $356 \mathrm{~Hz} / \mathrm{F} 1$ vowel offset: $355 \mathrm{~Hz}$; no significant effects). Note that there was no significant effect by the factor SYLLABLE.

To analyze the spectral qualities of the fricatives, FFT power spectra were calculated using a $50 \mathrm{~ms}$ Hann window that was centered over the mid part of the fricative (350-400 ms). From these spectra, COG and standard deviation (SD) were obtained. The spectral measures of the fricatives were analyzed by means of a multivariate ANOVA (MANOVA) with the between-items factors FRICATIVE and SYLLABLE as described before. A significant main effect of FRICATIVE indicates spectral differences between $[\mathrm{s}]$ and $[\mathrm{z}]$ (Pillai's trace $=0.532 ; F_{2,15}=8.5 ; p=0.003$; $\eta_{\mathrm{p}}^{2}=0.532$ ). The factor SYLLABLE did not show any significant effects. The univariate analyses revealed that voiceless fricatives were characterized by significantly higher COG frequencies ( $[\mathrm{s}]$ $\left.7712 \mathrm{~Hz} /[\mathrm{z}] 5908 \mathrm{~Hz}: F_{1,16}=10.9 ; p=0.004 ; \eta_{\mathrm{p}}^{2}=0.406\right)$, and lower SD ([s] 2094Hz/[z] $2730 \mathrm{~Hz}: F_{1,16}=14.0 ; p=0.002$; $\left.\eta_{\mathrm{p}}^{2}=0.466\right)$ compared to the voiced fricatives. Based on this we assumed that the voicing distinction in the stimulus material was sufficiently coded phonetically even though durational voicing cues had been neutralized by manipulation.

\section{EXPERIMENTAL DESIGN AND PROCEDURE}

As described above, four different experimental contrasts were employed: [vus] vs. [vusə] (contrast 1), [vus] vs. [vuzə] (contrast 2 ), ${ }^{*}$ [vuz] vs. [vusə] (contrast 3 ) and ${ }^{*}[$ vuz] vs. [vuzə] (contrast 4$)$. Each pair-wise contrast was presented twice in oddball sequences, both using one pseudoword as standard ( $85 \%$ of the trials $=1360$ items) and the other as deviant and the other way around (reversed oddball-design), resulting in eight experimental conditions. Oddball sequences of 1600 trials in total were presented per condition, using all tokens of each pseudoword equally. Standard and deviant stimuli were delivered in pseudorandomized order forcing at least two standards to be presented between successive deviants. Oddball conditions were then divided into two technical blocks each, resulting in a total of 16 stimulation blocks per participant. Sessions were split into two parts, so the second half of each condition was presented on a second day. Stimulus sequences were presented with a stimulus onset asynchrony randomly varying from 550 to $900 \mathrm{~ms}$ in units of $10 \mathrm{~ms}$. The order of the experimental blocks was counterbalanced between participants. Participants were seated comfortably in a sound-attenuated and electrically shielded experimental chamber, and they were instructed to ignore the auditory stimulation while watching a self-selected silent subtitled movie. Stimuli were presented binaurally at $53 \mathrm{~dB}$ SPL through headphones (Sennheiser HD 25-1 II; Sennheiser electronic GmbH \& Co. KG, Wedemark, Germany). Loudness was measured by means of an artificial head (artificial head HMS III.2; HEAD acoustics GmbH, Herzogenrath, Germany). All participants reported that they were able to ignore the auditory stimulation. Informal questioning of the participants revealed that they had perceived all stimulus types as speech sounds. A whole experimental session lasted approximately $180 \mathrm{~min}$ (plus additional time for electrode application and removal) including ten short breaks of about $2 \mathrm{~min}$ each.

\section{ELECTROPHYSIOLOGICAL RECORDINGS}

The EEG (Ag/AgCl electrodes, Falk Minow Services, V-Amp EEG amplifier; Brain Products GmbH, Gilching, Germany) was recorded continuously from 26 standard scalp locations according to the extended 10-20 system (American Encephalographic Society, 1994; FP1, FP2, F7, F3, FZ, F4, F8, FC5, FC1, FCZ, FC2, FC6, C3, CZ, C4, CP5, CP1, CP2, CP6, P7, P3, Pz, P4, P8, O1, $\mathrm{O} 2$ ) and from the left and right mastoids. The reference electrode was placed on the tip of the nose, and an additional electrode placed at AFZ was used as ground during recording. Electroocular activity was recorded with two bipolar electrode pairs, the vertical electrooculogram (EOG) was obtained from the right eye by one supraorbital and one infraorbital electrode and the horizontal EOG from electrodes placed lateral to the outer canthi of both eyes. Impedances were kept below $10 \mathrm{k} \Omega$. On-line band-pass filtering of the EEG and EOG signals was carried out using a $0.011 \mathrm{~Hz}$ high-pass and a $100 \mathrm{~Hz}$ low-pass filter. The signal was digitized with a 16 bit resolution at a sampling rate of $500 \mathrm{~Hz}$.

\section{DATA ANALYSIS}

Off-line signal processing was carried out using EEP 3.0 (ANT Neuro, Enschede, Netherlands). EEG-data were band-pass filtered with a finite impulse response filter: 4001 points, critical frequencies of $0.5 \mathrm{~Hz}$ (high-pass) and $15 \mathrm{~Hz}$ (low-pass; cf. Schröger, 2005). EEG epochs with a total length of $1050 \mathrm{~ms}$, time-locked to the onset of the stimuli and including a $100 \mathrm{~ms}$ pre-stimulus baseline, were extracted and averaged separately for each stimulus probability (standard, deviant), for each pseudoword, and for each participant.

The ERP responses to the first five stimuli per block as well as to each standard stimulus immediately following a deviant were not included in the analysis. Epochs showing an amplitude change exceeding $100 \mu \mathrm{V}$ at any of the recording channels were rejected. In the present study, an average of $15.1 \%$ (SD 6.2\%) of the trials per participant was rejected prior to ERP computation. Grandaverages were subsequently computed from the individual-subject averages.

To quantify the full MMN amplitude, the scalp ERPs were rereferenced to the averaged signal recorded from the electrodes 
positioned over the left and right mastoids. This computation results in an integrated measure of the total neural activity underlying the auditory MMN (e.g., Schröger, 2005).

Deviant-minus-standard difference waveforms were calculated for each pseudoword per oddball condition by subtracting the ERPs elicited by the standard point by point from the ERPs elicited by the original deviant obtained from the same oddball condition, i.e., the MMN elicited by [vusə] in condition 1a was quantified as difference between the deviant ERP from [vusə] and the standard ERP from [vus]. We opted for original contrasts from the same block in order to prevent superimposing effects from the block context to affect our comparisons.

Deviance-related effects (as the MMN) were quantified by measuring the ERP amplitudes as mean voltages in a fixed analysis window of $40 \mathrm{~ms}$ (for the width of the analysis window, cf. Luck, 2005, pp. 234). These windows were adjusted a posteriori on the basis of the grand-averaged deviance-minus-standard difference waves (cf. Picton et al., 2000). We adjusted separate windows for each condition and for each deviation by identifying the peak latencies of any distinguishable negative-going deflection (averaged across F3, Fz, F4, C3, Cz, and C4 electrode positions) within a priori determined time ranges. First, any effect due to the voicing alternation in the second fricative was expected to occur between 400 and $500 \mathrm{~ms}$ post stimulus onset (note that this latency equals 100 to $200 \mathrm{~ms}$ after the onset of the differing fricatives). This voicing alternation only occurs in contrasts 2 and 3. Second, deviations due to the presence or absence of the second vowel were expected to affect processing within the time range of 550 $650 \mathrm{~ms}$ post stimulus onset (i.e., 100-200 ms after the offset of the fricative/onset of the final vowel). In singular cases, additional earlier or later time windows were analyzed in an exploratory approach.

Statistical analyses were performed with SPSS (IBM SPSS Statistics 21). As the MMN is known to be maximal over frontal scalp areas (cf. Kujala et al., 2007), we decided to base our analyses only on the F-line positions by collapsing the ERPs obtained at F3, Fz, and F4 into one single measure. Separately for each analysis window, an overall univariate repeated-measures analysis of variance, henceforth ANOVA, was run including the within-subjects factors STIMULUS PROBABILITY (standard/deviant), CONTRAST (depends on the window), and VOWEL (additional vowel in the deviant is present/missing). Afterward, analyses were broken down if appropriate. Finally, comparisons between conditions relating to the hypotheses were performed using repeated-measures ANOVAs with the factors introduced above. Only significant main effects of the factor STIMULUS PROBABILITY and interactions with this factor were reported. The level of type 1 error was set to $p<0.05$ and, in case of multiple post hoc comparisons, Bonferroni correction was applied. If the sphericity assumption was violated (indicated by the Mauchly test), the original degrees of freedom were provided along with the Greenhouse-Geisser-epsilon. Finally, partial eta-squared $\left(\eta_{\mathrm{p}}^{2}\right)$ effect sizes were given for all significant effects.

\section{RESULTS}

The ERP results for all conditions are depicted in Figure 2. Also, this figure shows the respective analysis windows for each effect. The outcomes of the statistical analyses based on these windows are presented below separately for each analysis window. In Figure 3, topographical maps of the analyzed MMN effects are provided separately for each condition and time window.

\section{ANALYSIS OF THE VOICING CHANGE IN THE FRICATIVES (CONTRASTS 2 AND 3)}

For the MMN responses to the fricatives (FRIC in Figure 2) the overall ANOVA with the factors STIMULUS PROBABILTIY (standard/deviant), VOWEL (additional/missing), and CONTRAST $(2 / 3)$ revealed a significant main effect of the factor STIMULUS PROBABILITY $\left(F_{1,15}=17.9 ; p=0.001 ; \eta_{\mathrm{p}}^{2}=0.544\right)$, indicating the presence of an MMN across all conditions, and a significant interaction STIMULUS PROBABILITY*VOWEL*CONTRAST $\left(F_{1,15}=5.9 ; p=0.028 ; \eta_{\mathrm{p}}^{2}=0.284\right)$, indicating different amplitudes of the MMN responses across conditions. Brokendown analyses were calculated separately for each contrast: in contrast 2, the main effect for STIMULUS PROBABILITY $\left(F_{1,15}=9.1 ; p=0.009 ; \eta_{\mathrm{p}}^{2}=0.387\right)$, and also the interaction STIMULUS PROBABILITY*VOWEL $\left(F_{1,15}=5.9\right.$; $\left.p=0.028 ; \eta_{\mathrm{p}}^{2}=0.282\right)$ were significant, the latter indicating a stronger MMN response in condition 2a compared to condition 2b. In contrast 3, only a significant main effect for STIMULUS PROBABILITY was obtained $\left(F_{1,15}=9.3 ; p=0.008\right.$; $\left.\eta_{\mathrm{p}}^{2}=0.384\right)$.

\section{ANALYSIS OF THE EFFECT DUE TO THE CHANGE IN THE FINAL VOWEL (ALL CONTRASTS)}

For the MMN responses to the additional or missing vowel (VOW in Figure 2) the overall ANOVA with the factors STIMULUS PROBABILITY (standard/deviant), VOWEL (additional/missing), and CONTRAST (1/2/3/4) revealed a significant main effect for STIMULUS PROBABILITY $\left(F_{1,15}=25.0\right.$; $\left.p<0.001 ; \eta_{\mathrm{p}}^{2}=0.625\right)$, as well as significant interactions STIMULUS PROBABILITY*CONTRAST $\left(F_{3,45}=4.0\right.$; $\left.p=0.026 ; \varepsilon=0.725 ; \quad \eta_{\mathrm{p}}^{2}=0.209\right)$ and STIMULUS PROBABILITY*CONTRAST*VOWEL $\left(F_{3,45}{ }^{*}=3.1 ; p=0.039\right.$; $\left.\varepsilon=0.928 ; \eta_{\mathrm{p}}^{2}=0.172\right)$. Next, analyses were broken down by the factor VOWEL. Comparing the MMN amplitudes for the a-conditions, only a significant main effect for STIMULUS PROB$\operatorname{ABILTY}\left(F_{1,15}=9.3 ; p=0.008 ; \eta_{\mathrm{p}}^{2}=0.382\right)$ was found, but no interaction with this factor. For the b-conditions, the main effect STIMULUS PROBABILITY $\left(F_{1,15}=21.1 ; p<0.001 ; \eta_{\mathrm{p}}^{2}=0.585\right)$ and the interaction STIMULUS PROBABILITY*CONTRAST $\left(F_{3,45}=6.2 ; p=0.002 ; \varepsilon=0.880 ; \eta_{\mathrm{p}}^{2}=0.292\right)$ were significant. This interaction indicates differences in MMN amplitudes due to the missing final vowel across the contrasts. We a priori were only interested in potential differences between conditions $1 \mathrm{~b}$ and $3 \mathrm{~b}$, both sharing the same legal standard/vusə/. A broken-down ANOVA with STIMULUS PROBABILITY and CONTRAST (1/3) revealed a significant main effect for STIMULUS PROBABILITY $\left(F_{1,15}=35.4 ; p<0.001 ; \eta_{\mathrm{p}}^{2}=0.703\right)$, and a significant interaction between both factors $\left(F_{1,15}=5.1\right.$; $\left.p=0.039 ; \eta_{\mathrm{p}}^{2}=0.252\right)$, indicating stronger $\mathrm{MMN}$ amplitudes for $3 \mathrm{~b}$ compared to $1 \mathrm{~b}$. 


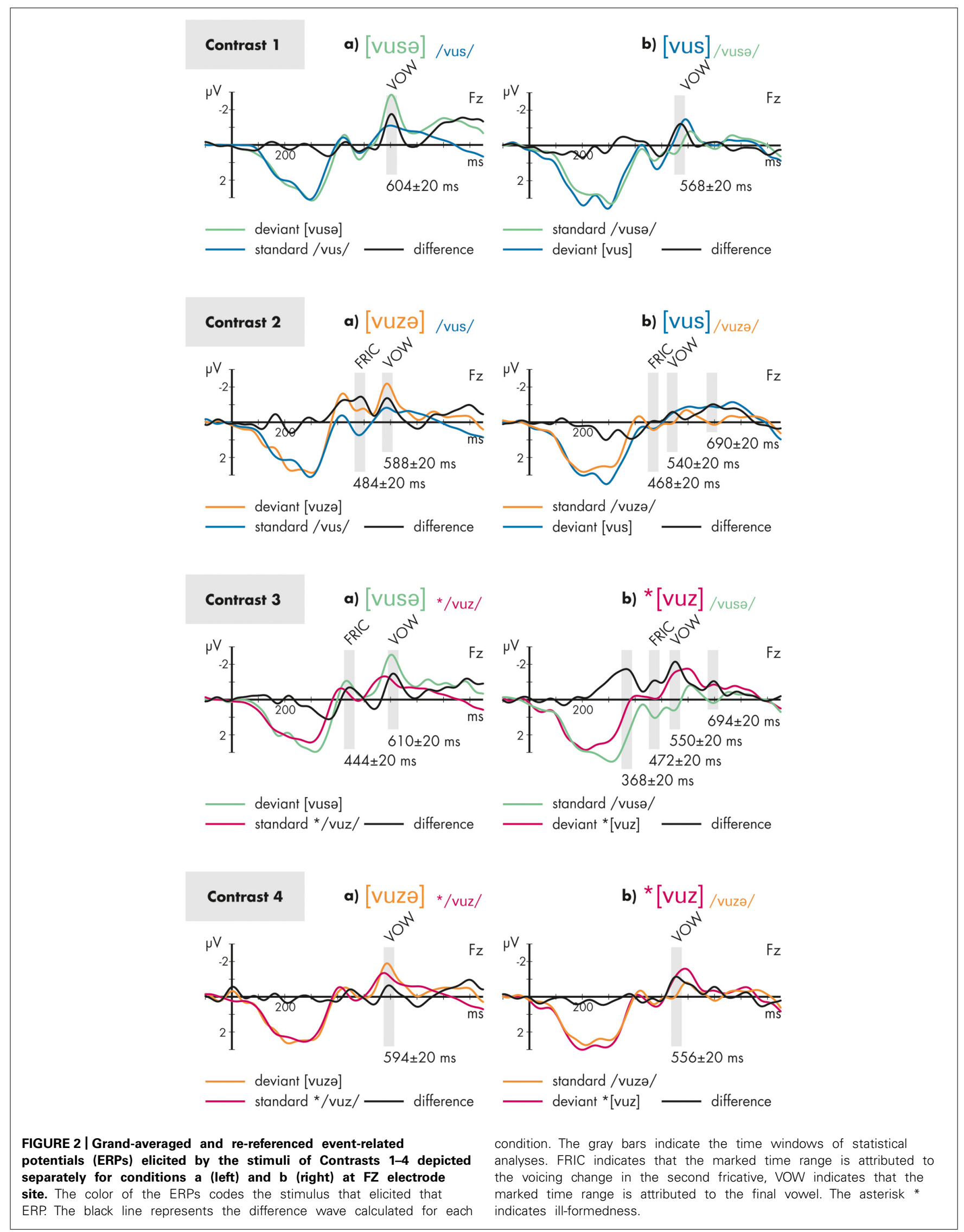




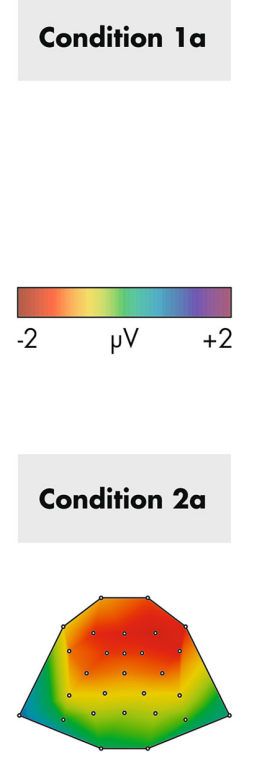

FRIC 484 20 ms

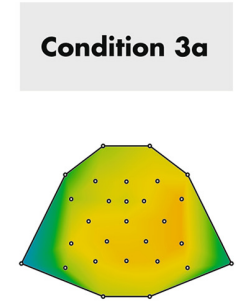

FRIC $444 \pm 20 \mathrm{~ms}$
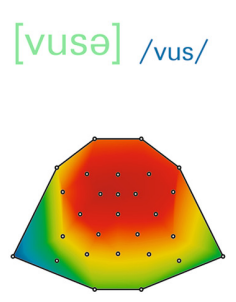

VOW $604 \pm 20 \mathrm{~ms}$
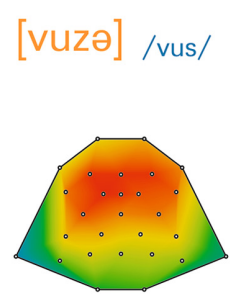

VOW $588 \pm 20 \mathrm{~ms}$
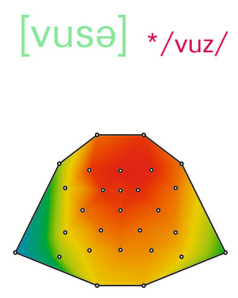

VOW $610 \pm 20 \mathrm{~ms}$

\section{Condition 4a}
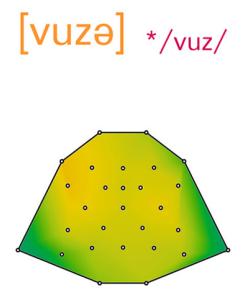

VOW $594 \pm 20 \mathrm{~ms}$

FIGURE 3 |Topographical maps of the analyzed deviance-minusstandard differences obtained from grand-averaged re-referenced data within the time windows stated below each map. Depicted are contrasts 1-4 separately for conditions a (left) and b (right). FRIC

\section{EXPLORATIVE ANALYSES OF EARLIER AND LATER EFFECTS (CONTRASTS 2 AND 3)}

In conditions $2 \mathrm{~b}$ and $3 \mathrm{~b}$, unexpected deviance-related effects were found in a time range later than $650 \mathrm{~ms}$ post stimulus onset. These effects were analyzed as described above: a significant main

\section{Condition 1b $\quad[$ vus $] /$ vusa/}

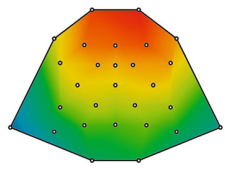

VOW $568 \pm 20 \mathrm{~ms}$

\section{Condition 2b [vus]/vuze/}

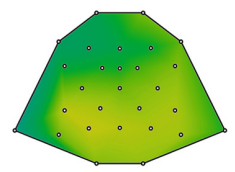

FRIC $468 \pm 20 \mathrm{~ms}$

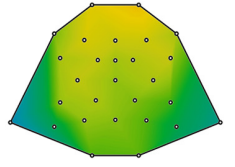

VOW $540 \pm 20 \mathrm{~ms}$

\section{Condition $3 b$}

$\star[\mathrm{vuz}]$

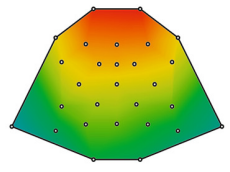

FRIC $472 \pm 20 \mathrm{~ms}$

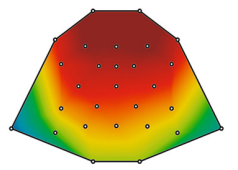

VOW $550 \pm 20 \mathrm{~ms}$

\section{Condition 4b}
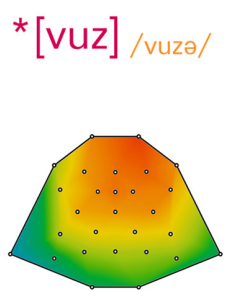

VOW $556 \pm 20 \mathrm{~ms}$

indicates that the marked time range is attributed to the voicing change in the second fricative, VOW indicates that the marked time range is attributed to the final vowel. The asterisk * indicates ill-formedness.

effect of STIMULUS PROBABILTIY $\left(F_{1,15}=19.5 ; p=0.001\right.$; $\left.\eta_{\mathrm{p}}^{2}=0.565\right)$ was found but no interactions with this factor. Because of its latency, it seems possible to us that this effect reflects morphological processing (see Royle et al., 2010). This is conceivable if the additional vowel is processed as a morphological suffix. 
Furthermore, a strong deviance-related effect was observed in condition $3 \mathrm{~b}$ that appeared in an unexpected early time range before $400 \mathrm{~ms}$, i.e., before the onset of the deviating fricative. Because of its latency, this effect seemed to be temporally related to the later part of the first vowel $[\mathrm{u}]$. This effect was compared with a corresponding time window in condition $1 \mathrm{~b}$ $(360 \pm 20 \mathrm{~ms})$ that shared the legal standard stimulus /vusə/. A significant main effect STIMULUS PROBABILITY $\left(F_{1,15}=39.1\right.$; $p<0.001 ; \eta_{\mathrm{p}}^{2}=0.722$ ) was found as well as a significant interaction STIMULUS PROBABILITY*CONTRAST $\left(F_{1,15}=9.0 ; p=0.009\right.$; $\left.\eta_{\mathrm{p}}^{2}=0.374\right)$, indicating a stronger deviance-related response in $3 \mathrm{~b}$ compared to $1 b$.

\section{DISCUSSION}

\section{REMARKS ON CONTRAST 1}

Our statistical assessment employed condition $1 \mathrm{~b}$ as a comparison condition for condition $3 \mathrm{~b}$ (see Evidence for the relevance of final devoicing in condition 3). However, contrast 1 (pairing the legal stimuli [vusə] and [vus] with no voicing change) is here also briefly considered on its own. Visual inspection of the difference waves for contrast 1 in Figure 2 shows distinct MMN responses that are attributable to the presence vs. absence of the final vowel, but no further effects, in particular no effects between 450 and $550 \mathrm{~ms}$ where differences attributable to the fricative would occur. This provides some assurance that effects attributed to fricatives in other conditions were not general consequences of our stimulus contrasts in which stimuli with and without a final vowel are compared. There is, for example, a distinction in syllabification. The a-conditions are syllabified like 1a: [vu.se] while the b-conditions are single syllables like 1b: [vus]. This distinction could in principle have phonetic correlates in regard to the extent of coarticulation of the $[\mathrm{s} / \mathrm{z}]$ with the preceding vowel. Recall that the phonetic analysis of the stimuli did not detect any such differences. Condition 1 suggests that such differences, if they exist after all, also did not lead to observable effects in the difference wave.

\section{EVIDENCE FOR THE RELEVANCE OF FINAL DEVOICING IN CONTRAST 2}

The following sketch shows condition $2 \mathrm{~b}$ next to condition $2 \mathrm{a}$. We included a dot to mark the syllable boundary in [vu.zə].

$\begin{array}{llll}\text { 2a: } & \text { Standard } & \begin{array}{l}\text { Deviant } \\ \text { [vu.zə] }\end{array} & \begin{array}{l}\text { Comment } \\ \text { significantly stronger effect for } \\ \text { voicing change than in } 2 \mathrm{~b}\end{array} \\ \text { 2b: } & \text { /vu.zə/ } & \text { [vus }] & \text { related by final devoicing }\end{array}$

There is a significant difference between conditions $2 \mathrm{a}$ and $2 \mathrm{~b}$ in the processing correlates of the voicing change in the fricative. The MMN effect due to the voicing mismatch in condition 2 a was absent in condition $2 \mathrm{~b}$, where the voicing change was motivated by FD. This significant difference between conditions $2 \mathrm{a}$ and $2 \mathrm{~b}$ is here interpreted as evidence for the relevance of FD in pre-attentive processing.

\section{REMARKS ABOUT REACTIONS TO THE FINAL VOWEL IN CONDITION 2b}

We turn to some remarks about the MMN response due to the additional $/$ missing vowel in conditions $2 \mathrm{a}$ and $2 \mathrm{~b}$. The plots in
Figure 2 suggest that the response attributable to the missing final vowel in the deviant of condition $2 \mathrm{~b}$ was also reduced. We here want to comment this impression for the benefit of possible future experiments that might investigate such an effect more specifically. The observation suggests that the expectation of any upcoming auditory event, which is violated in the deviant and shown by the MMN, is not limited to the expectation of just another standard stimulus. It seems, instead, that this expectation can be modulated by what is found earlier in the deviant. The system seems to have related /vuzə/ and [vus] by FD. If the system possesses knowledge of the environment of FD, it will then expect the absence of a vowel following [vus], since FD would not have applied in the presence of a following vowel. (Similar expectations could also be modulated by phonetic factors that might allow the anticipation of the absence of a final vowel. However, the reduced MMN response to the missing final vowel seems to be specific to condition $2 b$, where FD has applied.) It is also possible, then, that the standard /vuz $+2 /$ and the deviant [vus] were processed as morphologically related by the omission of an inflectional element [ə] in the deviant, with phonological adjustment due to FD. It seems conceivable that this was related to the late deviance-related effect that was observed about $250 \mathrm{~ms}$ after the missing vowel had become detectable.

We note that we have argued (Jacobsen et al., 2013) against the assumption of successive MMN responses in case of mismatching monosyllabic vowel-consonant sequences, where both the vowel and the consonant differed. However, the case at hand is different in an important aspect: the second deviation in the present contrast pairs, namely the missing or additional final vowel in contrasts 2 and 3, did not just involve a distinct sound, but established a distinction in syllable structure between standard and deviant. By this, the present stimulus contrasts were clearly different not just at the segmental but also at suprasegmental representation levels.

\section{EVIDENCE FOR THE RELEVANCE OF FINAL DEVOICING IN CONDITION 3}

It was seen in the presentation of the results that condition $3 \mathrm{~b}$ and condition $1 \mathrm{~b}$ both have MMN responses attributable to the missing vowel, and that both effects furthermore differ significantly in strength. This is illustrated in the following sketch.

$\begin{array}{cccl}\text { 1b: } & \text { Standard } & \text { Deviant } & \text { Comment } \\ & \text { [vus] } & \begin{array}{l}\text { significant effect for missing final } \\ \text { vowel }\end{array} \\ \text { 3b: } & \text { susə/ } & *[\mathrm{vuz}] & \begin{array}{l}\text { significantly stronger effect for } \\ \text { missing final vowel }\end{array}\end{array}$

It was suggested that this is evidence for a superposed effect of the ill-formedness of the deviant ${ }^{*}$ [vuz] in condition $3 \mathrm{~b}$, which becomes manifest in the signal simultaneously with the absence of the final vowel. This distinction provides further evidence for the relevance of FD in pre-attentive processing.

\section{REMARKS ON REACTIONS TO THE FIRST VOWEL IN CONDITION 3}

The comparison between conditions $1 \mathrm{~b}$ and $3 \mathrm{~b}$ is repeated in the following, this time highlighting a significant distinction that was found post hoc: condition $3 \mathrm{~b}$ showed an effect at the time at which 
the second part of the vowel $[\mathrm{u}]$ is expected to be processed. The distinction to $1 \mathrm{~b}$ was seen to be significant.

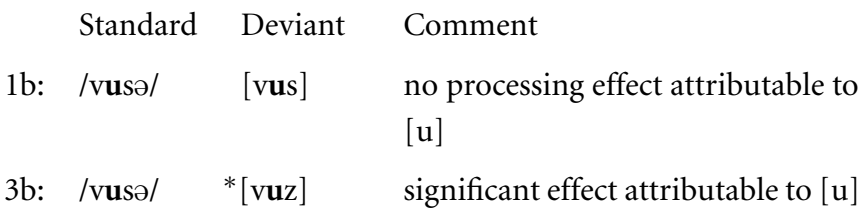

This effect in $3 b$ may be related to the anticipation of $[z]$ during the vowel $[\mathrm{u}]$ due to coarticulatory cues. It is furthermore possible that phonetic factors allowed an early prediction of the syllable structure. The system might have noticed in *[vuz] during the vowel that there would be an upcoming voiced fricative within the same syllable, in violation of FD. If so, the early strong MMN effect before $400 \mathrm{~ms}$ in condition $3 \mathrm{~b}$ might already be a first electrophysiological response to the ill-formedness of the deviant.

\section{SUMMARY}

In summary, we have found two pieces of evidence for the role of FD in pre-attentive processing. While condition $2 \mathrm{a},[\mathrm{vuz}] / \mathrm{vus} /$, showed mismatch effects due to the voicing change in the fricative, these are significantly reduced (and in fact absent) in condition $2 \mathrm{~b},[\mathrm{vus}]_{/ \mathrm{vuz} /}$, in which the two forms can be related by FD. In condition $3 \mathrm{~b},{ }^{*}[\mathrm{vuz}]_{\text {/vusə/, }}$, an overlaid effect of the violation of FD in the deviant * [vuz] was found.

An interesting aspect of our findings is that they provide evidence that syllable-related lexical phenomena such as FD are already taken into account by the processing system in an early pre-attentive stage. This point is new insofar the only previous study we are aware of that showed the processing relevance of a syllable-related process is Dehaene-Lambertz et al. (2000), which did not employ a pre-attentive protocol.

\section{ACKNOWLEDGMENTS}

This work was supported by the DFG SPP 1234 grant JA1009/102 to Thomas Jacobsen and Hubert Truckenbrodt and by the German Federal Ministry of Education and Research (BMBF), Grant Nr. 01UG1411. The authors are grateful to Jana Burock, Susan Beudt, Johannes Frey, Svantje Kähler, Aquiles LunaRodriguez, Jonathan Manske, Falco Walther, Mike Wendt and Lena Zielonka for technical help and valuable comments.

\section{REFERENCES}

American Encephalographic Society. (1994). Guideline thirteen: guidelines for standard electrode position nomenclature. J. Clin. Neurophysiol. 11, 111-113. doi: 10.1097/00004691-199401000-00014

Beckman, J., Jessen, M., and Ringen, C. (2009). German fricatives: coda devoicing or positional faithfulness? Phonology 26, 231-268. doi: 10.1017/S0952675709 990121

Boersma, P., and Weenink, D. (2010). Praat: Doing Phonetics by Computer (Version 5.1.44) [Computer Program]. Available at: http://www.praat.org/ [accessed October 20, 2010]

Cornell, S. A., Lahiri, A., and Eulitz, C. (2011). What you encode is not necessarily what you store: evidence for sparse feature representations from mismatch negativity. Brain Res. 1394, 79-89. doi: 10.1016/j.brainres.2011. 04.001
Cornell, S. A., Lahiri, A., and Eulitz, C. (2013). Inequality across consonantal contrasts in speech perception: evidence from mismatch negativity. J. Exp. Psychol. Hum. Percept. Perform. 39, 757-772. doi: 10.1037/a0030862

Dehaene-Lambertz, G., Dupoux, E., and Gout, A. (2000). Electrophysiological correlates of phonological processing: a cross-linguistic study. J. Cogn. Neurosci. 12, 635-647. doi: 10.1162/089892900562390

Eulitz, C., and Lahiri, A. (2004). Neurobiological evidence for abstract phonological representations in the mental lexicon during speech recognition. J. Cogn. Neurosci. 16, 577-583. doi: 10.1162/089892904323057308

Flagg, E. J., Cardy, J. E. O., and Roberts, T. P. L. (2006). MEG detects neural consequences of anomalous nasalization in vowel-consonant pairs. Neurosci. Lett. 397, 263-268. doi: 10.1016/j.neulet.2005.12.034

Hall, T. A. (1992). Syllable Structure and Syllable-Related Processes in German. Tübingen: Max Niemeyer. doi: 10.1515/9783111657882

Hwang, S.-O. K., Monahan, P., and Idsardi, W. (2010). Underspecification and asymmetries in voicing perception. Phonology 22, 205-224. doi: $10.1017 /$ S0952675710000102

Itô, J. (1986). Syllable Theory in Prosodic Phonology. New York: Garland Publishing. Jacobsen, T., Schröger, E., and Alter, K. (2004). Pre-attentive perception of vowel phonemes from variable speech stimuli. Psychophysiology 41, 654-659. doi: 10.1111/1469-8986.2004.00175.x

Jacobsen, T. K., Steinberg, J., Truckenbrodt, H., and Jacobsen, T. (2013). Mismatch negativity (MMN) to successive deviants within one hierarchically structured auditory object. Int. J. Psychophysiol. 87, 1-7. doi: 10.1016/j.ijpsycho.2012.09.012

Jessen, M. (1998). Phonetics and Phonology of Tense and Lax Obstruents. Amsterdam: John Benjamins.

Jessen, M., and Ringen, C. (2002). Laryngeal features in German. Phonology 19, 189-218. doi: 10.1017/S0952675702004311

Kujala, T., Tervaniemi, M., and Schröger, E. (2007). The mismatch negativity in cognitive and clinical neuroscience: theoretical and methodological considerations. Biol. Psychol. 74, 1-19. doi: 10.1016/j.biopsycho.2006.06.001

Lombardi, L. (1991). Laryngeal Features and Laryngeal Neutralization. Ph.D. thesis, University of Massachusetts, Amherst.

Lombardi, L. (1999). Positional faithfulness and voicing assimilation in optimality theory. Nat. Lang. Linguist. Theory 17, 267-302. doi: 10.1023/A:1006182130229

Luck, S. J. (2005). An Introduction to the Event-Related Potential Technique. Cambridge, MA: MIT Press.

Maniwa, K., and Jongman, A. (2009). Acoustic characteristics of clearly spoken English fricatives. J. Acoust. Soc. Am. 125, 3962-3973. doi: 10.1121/1.2990715

Mitterer, H., and Blomert, L. (2003). Coping with phonological assimilation in speech perception: evidence for early compensation. Percept. Psychophys. 65, 956-969. doi: 10.3758/BF03194826

Näätänen, R. (1992). Attention and Brain Fuction. Hillsdale: Lawrence Erlbaum.

Näätänen, R. (2001). The perception of speech sounds by the human brain as reflected by mismatch negativity (MMN) and its magnetic equivalent (MMNm). Psychophysiology 38, 1-21. doi: 10.1111/1469-8986.3810001

Näätänen, R., Lehtokoski, A., Lennes, M., Cheour, M., Huotilainen, M., Iivonen, A., et al. (1997). Language-specific phoneme representations revealed by electric and magnetic brain responses. Nature 385, 432-434. doi: 10.1038/385432a0

Obleser, J., Lahiri, A., and Eulitz, C. (2004). Magnetic brain response mirrors extraction of phonological features from spoken vowels. J. Cogn. Neurosci. 16, 31-39. doi: 10.1162/089892904322755539

Oldfield, R. C. (1971). The assessment and analysis of handedness: the Edinburgh inventory. Neuropsycholologia 9, 97-113. doi: 10.1016/0028-3932(71)90067-4

Peltola, M. S., Kujala, T., Tuomainen, J., Ek, M., Aaltonen, O., and Näätänen, R. (2003). Native and foreign vowel discrimination as indexed by the mismatch negativity (MMN) response. Neurosci. Lett. 352, 25-28. doi: 10.1016/j.neulet.2003.08.013

Phillips, C., Pellathy, T., Marantz, A., Yellin, E., Wexler, K., Poeppel, D., et al. (2000). Auditory cortex accesses phonological categories: an MEG mismatch study. J. Cogn. Neurosci. 12, 1038-1055. doi: 10.1162/08989290051137567

Picton, T. W., Bentin, S., Berg, P., Donchin, E., Hillyard, S. A., Johnson, R. Jr., et al. (2000). Guidelines for using human event-related potentials to study cognition: recording standards and publication criteria. Psychophysiology 37, 127-152. doi: 10.1111/1469-8986.3720127

Poeppel, D., and Monahan, P. J. (2011). Feedforward and feedback in speech perception: revisiting analysis by synthesis. Lang. Cogn. Process. 26, 935-951. doi: 10.1080/01690965.2010.493301 
Port, R. F., and O’Dell, M. L. (1985). Neutralization of syllable-final voicing in German. J. Phon. 13, 455-471.

Roberts, T. P., Flagg, E. J., and Gage, N. M. (2004). Vowel categorization induces departure of M100 latency from acoustic predictions. Neuroreport 15, 1679-1682. doi: 10.1097/01.wnr.0000134928.96937.10

Royle, P., Drury, J. E., Bourguignon, N., and Steinhauer, K. (2010). “Morphology and word recognition: an ERP approach," in Proceedings of the 2010 Annual Conference of the Canadian Linguistic Association, Concordia University, Montreal. Available at: http://homes.chass.utoronto.ca/ cla-acl/actes2010/actes2010.html

Rubach, J. (1990). Final devoicing and cyclic syllabification in German. Linguist. Inq. 21, 79-94.

Scharinger, M., Bendixen, A., Trujillo-Baretto, N. J., and Obleser, J. (2012). A sparse neural code for some speech sounds but not for others. PLoS ONE 7:e40953. doi: 10.1371/journal.pone.0040953

Schröger, E. (2005). The mismatch negativity as a tool to study auditory processing. Acta Acust. United Acust. 91, 490-501.

Sharma, A., and Dorman, M. F. (2000). Neurophysiologic correlates of crosslanguage phonetic perception. J. Acoust. Soc. Am. 107, 2697-2703. doi: $10.1121 / 1.428655$

Steinberg, J., Truckenbrodt, H., and Jacobsen, T. (2010a). Preattentive phonotactic processing as indexed by the mismatch negativity. J. Cogn. Neurosci. 22, 2174 2185. doi: 10.1162/jocn.2009.21408

Steinberg, J., Truckenbrodt, H., and Jacobsen, T. (2010b). Activation and application of an obligatory phonotactic constraint in German during automatic speech processing is revealed by human event-related potentials. Int. J. Psychophysiol. 77, 13-20. doi: 10.1016/j.ijpsycho.2010.03.011

Steinberg, J., Truckenbrodt, H., and Jacobsen, T. (2011). Phonotactic constraint violations in German grammar are detected automatically in auditory speech processing: a human event-related potentials study. Psychophysiology 48, 12081216. doi: 10.1111/j.1469-8986.2011.01200.x

Steinberg, J., Truckenbrodt, H., and Jacobsen, T. (2012). The role of stimulus cross-splicing in an event-related potentials study. Misleading formant transitions hinder automatic phonological processing. J. Acoust. Soc. Am. 131, 3120-3140. doi: $10.1121 / 1.3688515$
Steriade, D. (1997). Phonetics in Phonology: The Case of Laryngeal Neutralization. Manuscript, UCLA. Available at: http://www.linguistics.ucla.edu/people/steriade/ papers/PhoneticsInPhonology.pdf

Stevens, K. N., Blumstein, S. E., Glicksman, L., Burton, M., and Kurowski, K. (1992). Acoustic and perceptual characteristics of voicing in fricatives and fricative clusters. J. Acoust. Soc. Am. 91, 2979-3000. doi: 10.1121/ 1.402933

Vaux, B. (1998). The laryngeal specifications of fricatives. Linguist. Inq. 29, 497-511. doi: $10.1162 / 002438998553833$

Winkler, I., Lehtokoski, A., Alko, P., Vainio, M., Czigler, I., Csépe, V., et al. (1999). Preattentive detection of vowel contrasts utilizes both phonetic and auditory memory representations. Cogn. Brain Res. 7, 357-369. doi: 10.1016/S0926-6410(98) 00039-1

World Medical Association. (2013). World Medical Association Declaration of Helsinki - Ethical Principles for Medical Research Involving Human Subjects. Available at: http://www.wma.net/en/30publications/10policies/b3/

Conflict of Interest Statement: The authors declare that the research was conducted in the absence of any commercial or financial relationships that could be construed as a potential conflict of interest.

Received: 23 May 2014; accepted: 29 October 2014; published online: 25 November 2014.

Citation: Truckenbrodt H, Steinberg J, Jacobsen TK and Jacobsen T (2014) Evidence for the role of German final devoicing in pre-attentive speech processing: a mismatch negativity study. Front. Psychol. 5:1317. doi: 10.3389/fpsyg.2014.01317

This article was submitted to Language Sciences, a section of the journal Frontiers in Psychology.

Copyright (c) 2014 Truckenbrodt, Steinberg, Jacobsen and Jacobsen. This is an openaccess article distributed under the terms of the Creative Commons Attribution License (CC BY). The use, distribution or reproduction in other forums is permitted, provided the original author(s) or licensor are credited and that the original publication in this journal is cited, in accordance with accepted academic practice. No use, distribution or reproduction is permitted which does not comply with these terms. 